\author{
А. Махлюф \\ Российский экономический университет имени Г. В. Плеханова, \\ Москва, Россия
}

В статье рассмотрен принцип комплексного развития туризма, включающий в себя три основных аспекта: устойчивое развитие, использование информационных технологий, правильное планирование туризма. Потенциал принципа комплексного развития туризма рассматривается на примере туристского сектора Сирии, который уже более восьми лет переживает кризис. Автором изложена стратегия, принятая сирийским Министерством туризма с целью смягчения негативного воздействия на сектор туризма и гостеприимства в условиях политико-экономического кризиса в стране. Статья включает в себя множество статистических данных туристских и гостиничных услуг, которые демонстрируют результаты, достигнутые в сирийском туристском секторе. Эти результаты стали возможными благодаря постоянной работе сирийского Министерства туризма по сохранению места Сирии на международной карте туризма. Международное культурно-историческое сотрудничество в области туризма может служить ролевой моделью для стран в условиях политико-экономической нестабильности.

Ключевые слова: туризм, устойчивый туризм, устойчивое гостеприимство, развитие гостеприимства, условия нестабильности.

\title{
MODERN TECHNIQUES AND METHODS TO ENSURE THE DEVELOPMENT OF TOURISM AND HOTEL ENTERPRISES IN THE SYRIAN ARAB REPUBLIC
}

\author{
Aghiad Makhlouf \\ Plekhanov Russian University of Economics, \\ Moscow, Russia
}

\begin{abstract}
This article discusses the principle of integrated tourism development, based on three aspects: sustainable tourism, the use of information technology, proper tourism planning. These three principles are integrated and cannot be separated. The article discusses the situation of the Syrian tourism sector in this sector, which for more than 8 years has been experiencing numerous crises and conditions of instability. The article outlines the strategy adopted by the Syrian Ministry of Tourism in order to mitigate the negative impact on the tourism and hospitality sector as a result of instability in the country. The article includes many tourist and hotel statistics that show the results achieved in the tourism sector and hotels in Syria. These results were achieved thanks to the ongoing work of the Syrian Ministry of Tourism in maintaining the location of Syria in the international tourism map. The scientific importance of this article lies in the fact that it serves as an example to follow for any country that may be in conditions of instability and numerous crises. This article explains the importance of tourism planning in order to be able to act in conditions of instability, so the work falls on both the public and the private sector.

Keywords: tourism, sustainable tourism, sustainable hospitality, hospitality development, instability conditions.
\end{abstract}




\section{Введение}

Пуризм является наиболее уязвимым сектором экономики в условиях войн. Именно в сфере туризма негативные эффекты политической и экономической нестабильности проявляются быстрее всего, и этому сектору требуется больше времени для полного восстановления. Вместе с тем существуют стратегии, которые можно применять для смягчения негативных последствий нестабильности в сфере туризма. Большинство подобных стратегий базируются на принципе комплексного развития туризма. Реализация данного принципа в управлении туристскими и гостиничными предприятиями способствует созданию рабочих мест, улучшению платежного баланса и повышению доходов.

\section{Элементы концепции комплексного развития туризма}

Успех развития индустрии туризма и гостеприимства в настоящее время зависит от реализации трех основных элементов концепции комплексного развития туризма (рис. 1):

1) устойчивого развития туризма;

2) стратегического планирования в индустрии туризма и гостеприимства;

3) применения информационных и коммуникационных технологий (ИКТ) в сфере туризма и гостеприимства (е-туризм, е-маркетинг и цифровая экономика) [6. - C. 7-28].

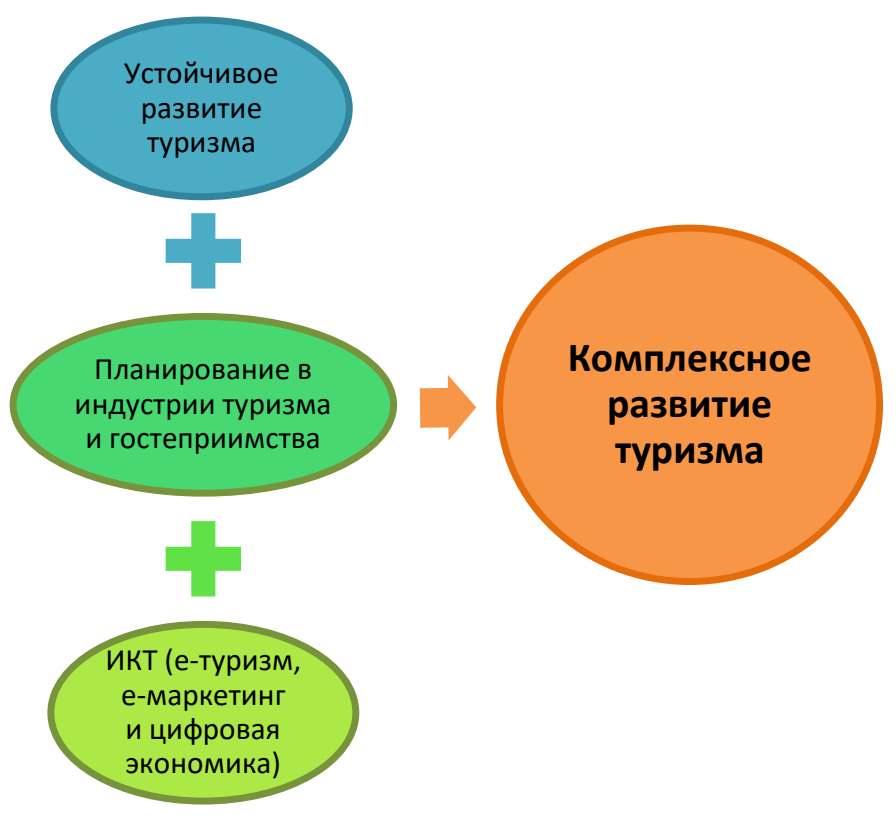

Рис. 1. Элементы концепции комплексного развития туризма

Устойчивое развитие туризма требует активного участия всех заинтересованных сторон, в том числе вовлеченности политических элит для обеспечения широкого участия различных акторов и формирования консенсуса. Обеспечение устойчивого туризма - это непрерывный процесс, и он требует постоянного мониторинга состояния отрасли, что в случае необходимости позволяет вовремя принять предупредительные и/или корректирующие меры.
Реализации принципа устойчивого туризма способствует возрастающая готовность населения платить за устойчивые продукты и услуги, отвечающие принципам ответственного производства, которая повсеместно увеличилась с 2011 г. В глобальном масштабе процент потребителей, готовых платить дополнительные средства за подобные продукты и услуги, увеличился с $45 \%$ в 2012 г. до 55\% в 2015 г. [5]. 
Интересно отметить, что данный показатель ниже в самых богатых частях мира, а именно в Северной Америке и Европе, где соответственно только 42 и $40 \%$ потре- бителей готовы принять более высокие цены на товары социально ответственных компаний (рис. 2).

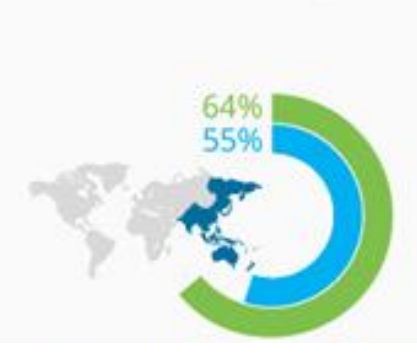

Азия/Тихоокеанский регион

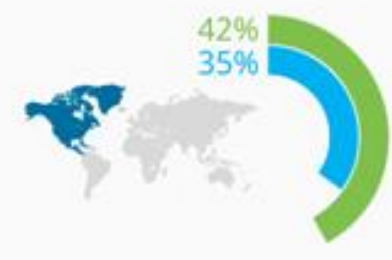

Северная Америка

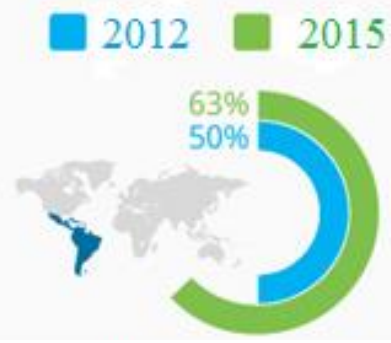

Латинская Америка

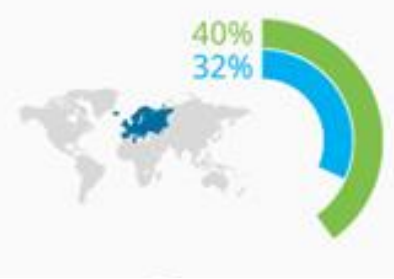

Европа

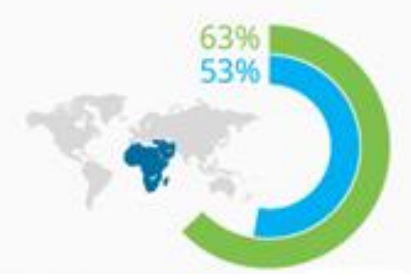

Средний Восток/Африка

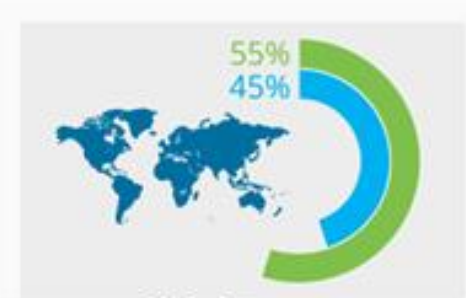

Глобальное среднее

Рис. 2. Готовность населения платить за услуги по странам

Источник: URL: https:/ / www.statista.com/chart/2401/willingness-to-pay-for-sustainable-products/

На рис. 2 показан процент потребителей, которые готовы платить больше за товары и услуги тех компаний, которые придерживались принципов позитивного социального и экологического воздействия в период 2012-2015 гг.

Планирование в индустрии туризма и гостеприимства включает анализ потребностей людей, планирующих поездку, и использование результатов этого анализа для выстраивания лучших туристских предложений. Планирование туризма оказывает положительный эффект как на местных жителей, так и на туристов. Как правило, в рамках планирования туризма учитывается комплексный набор факторов, начиная с поиска помещений для удовлетворения различных потребностей путешественников и заканчивая подбором специальных программ и мероприятий [7].
Развитие информационных и коммуникационных технологий в последние десятилетия способствовало значительному росту индустрии туризма, в том числе электронных платформ. Сейчас электронный туризм является одним из основных источников дохода для многих стран [4].

Считается, что технологии социальных медиа создали глобальное пространство, характеризующееся плотными виртуальными связями. Предоставляя онлайнвозможности для преодоления физических расстояний, новые технологии создают бесчисленные возможности для процветания индустрии путешествий и туризма.

Охват социальными сетями в мире постоянно растет. В 2016 г. 68,3\% интернетпользователей были пользователями социальных сетей, и ожидается, что эта цифра будет только расти [3]. Социальные сети являются одним из самых популярных он- 
лайн-сервисов с высокой степенью вовлеченности пользователей и расширенными возможностями использования мобильной связи (рис. 3).

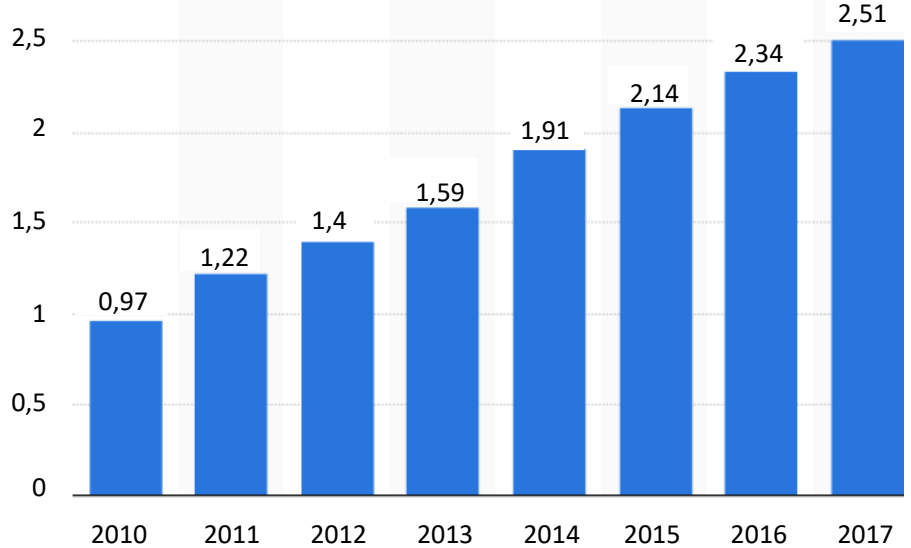

Рис. 3. Количество пользователей социальных сетей в мире в период с 2010 по 2017 г. (в млрд чел.)

Источник: URL: https:/ /www.statista.com/statistics/278414/number-of-worldwide-social-network-users/

\section{Анализ гостиничного рынка}

\section{Сирийской Арабской Республики}

Туризм в Сирии до войны являлся одним из ключевых секторов экономики, составляющий почти 13,5\% валового внутреннего продукта страны (по состоянию на 2010 г.).

Анализируя важнейшие экономические показатели, данные по которым доступны, в том числе за годы войны, можно отметить следующее:
- вклад туристского сектора составляет около $34 \%$ в торговом балансе за счет экспорта товаров;

- на сектор туризма приходится 78\% экспорта услуг;

- туризм и ресторанный бизнес способствуют созданию 110 тыс. новых рабочих мест.

Данные о количестве гостиничных номеров и/или спальных зон приведены в табл. 1.

Т а б лица 1

Общее количество отелей в городах в соответствии с их классификацией в 2010 г.*

\begin{tabular}{|c|c|c|c|c|c|c|c|c|}
\hline \multirow{2}{*}{$\begin{array}{c}\text { Общее количество } \\
\text { комнат по городу }\end{array}$} & \multirow{2}{*}{$\begin{array}{c}\text { Всего } \\
\text { отелей }\end{array}$} & \multirow{2}{*}{$\begin{array}{c}\text { Нет } \\
\text { звезд }\end{array}$} & \multicolumn{5}{|c|}{ Количество звезд } & \multirow{2}{*}{ Город } \\
\hline & & & 1 & 2 & 3 & 4 & 5 & \\
\hline 1600 & 60 & 15 & 12 & 9 & 8 & 10 & 6 & Дамаск \\
\hline 1400 & 49 & 12 & 10 & 8 & 7 & 8 & 4 & Алеппо \\
\hline 600 & 35 & 8 & 9 & 4 & 5 & 7 & 2 & Хомс \\
\hline 300 & 23 & 3 & 5 & 3 & 3 & 8 & 1 & Хама \\
\hline 800 & 43 & 7 & 7 & 7 & 10 & 8 & 4 & Латакия \\
\hline 200 & 31 & 9 & 3 & 5 & 7 & 6 & 1 & Аль Хасака \\
\hline 700 & 39 & 6 & 6 & 7 & 8 & 9 & 3 & Тартус \\
\hline 200 & 18 & 1 & 4 & 2 & 5 & 5 & 1 & Эс-Сувайда \\
\hline 5800 & 298 & 64 & 56 & 45 & 61 & 53 & 22 & Общее число \\
\hline
\end{tabular}

* Источник: URL: https://sy.aliqtisadi.com/related/80015 
В 2010 г., до начала войны, общее количество спальных мест в Сирии составляло 10 733. Начиная с 2011 г. и до конца 2018 г. наблюдалось значительное сокращение количества спальных мест, вызванное выведением из строя множества туристских и гостиничных объектов (табл. 2).

Т а б ли а 2

Общее количество отелей в городах в соответствии с их классификацией в 2018 г.*

\begin{tabular}{|c|c|c|c|c|c|c|c|c|}
\hline \multirow{2}{*}{$\begin{array}{c}\text { Общее количество } \\
\text { комнат по городу }\end{array}$} & \multirow{2}{*}{ Всего } & \multirow{2}{*}{ отет } & \multicolumn{7}{|c|}{ Количест } & звезд & $\mathbf{1}$ & $\mathbf{2}$ & $\mathbf{3}$ & $\mathbf{4}$ & $\mathbf{5}$ & \multirow{2}{*}{ Город } \\
\hline 1100 & 46 & 8 & 10 & 8 & 6 & 8 & 6 & Дамаск \\
\hline 900 & 36 & 5 & 9 & 7 & 5 & 6 & 4 & Алеппо \\
\hline 400 & 28 & 4 & 8 & 4 & 4 & 6 & 2 & Хомс \\
\hline 200 & 22 & 3 & 5 & 3 & 2 & 8 & 1 & Хама \\
\hline 700 & 38 & 5 & 5 & 7 & 10 & 7 & 4 & Латакия \\
\hline 100 & 27 & 9 & 3 & 4 & 5 & 5 & 1 & Аль Хасака \\
\hline 600 & 39 & 5 & 6 & 9 & 8 & 8 & 3 & Тартус \\
\hline 150 & 18 & 1 & 4 & 2 & 5 & 5 & 1 & Эс-Сувайда \\
\hline 4150 & 254 & 40 & 50 & 44 & 50 & 53 & 22 & Общее число \\
\hline
\end{tabular}

* Источник: URL: https://sy.aliqtisadi.com/related/80015

Как видно из табл. 2, в 2018 г. общее количество спальных мест в Сирии составило 4 150. Это означает, что нехватка спальных мест в период 2010-2018 гг. составляла 1650 мест.

Таким образом, мы наблюдаем значительные потери в секторе туризма и гостеприимства в Сирии, вызванные войной и политико-экономической нестабильностью.

Существуют ли решения, способные в перспективе улучшить статус сирийского туризма на ближневосточном туристском рынке, где ключевыми игроками сейчас являются Ливан, Иордания и Турция?

\section{Стратегия Министерства туризма \\ Сирии по выходу}

\section{из политико-экономического кризиса}

Что касается планирования туризма, то сирийское правительство сделало ставку на конкретные механизмы развития и реконструкции туризма:

- проведение работ по реконструкции поврежденных в результате террористиче- ских актов зданий и туристских объектов, принадлежащих государству и частным собственникам;

- поддержка малого и среднего предпринимательства в сфере туризма, направленного в том числе на сохранение и развитие местных сообществ;

- корректировка и рационализация государственных расходов на туристские проекты [2];

- привлечение национальных инвестиций в сектор туризма и гостеприимства;

- укрепление связей с местными (правительственные организации, учреждения и университеты) и глобальными (дружественные Сирии страны: Россия, Китай, Индия) партнерами для реализации совместных проектов в сфере реконструкции и создания инфраструктурных объектов;

- взаимодействие с международными организациями с целью расширения туристских связей и создания практических основ для роста инвестиций в туристскую отрасль. 
Согласно имеющимся данным, с начала 2018 г. 80 российских инвестиционных компаний заинтересовались развитием ту- ризма на сирийской территории. На рис. 4 представлены наиболее важные партнеры Сирии в 2017 г.

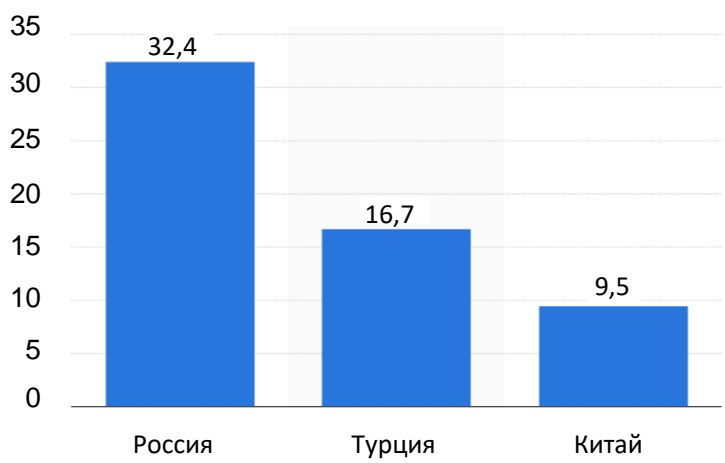

Рис. 4. Основные зарубежные партнеры Сирии в 2017 г. (в \%)

Источник: URL: https:/ /www.statista.com/statistics/326629/most-important-import-partners-of-syria/

\section{Международное}

\section{культурно-историческое}

\section{сотрудничество в области туризма}

Переходя к конкретным мерам по поддержке развития индустрии туризма в Сирии, отметим, что во время кризиса большинство туристских, культурных и археологических объектов были повреждены в ходе террористических атак. Одним из самых печально известных актов вандализма против памятников культуры стало разрушение Пальмиры, памятника Всемирного наследия ЮНЕСКО. Сирийское правительство уже объявило о планах по частичному восстановлению Пальмиры в течение 2019 г., а пока российское правительство оказывает Сирии активную культурную поддержку в этой области. Так, в мае 2016 г. в амфитеатре Пальмиры состоялся концерт оркестра Мариинского театра.

Михаил Пиотровский, генеральный директор всемирно известного российского музея «Эрмитаж», заявил, что музей готов помочь в разработке проекта по восстановлению сирийского древнего города Тадмур после освобождения его территории от террористов. Глава Эрмитажа отметил, что повреждение Пальмиры следует предварительно оценить, подчеркнув, что специалисты музея как крупнейшего научно- го учреждения готовы обсудить различные проекты реставрации.

Со своей стороны представитель президента России по международному культурному сотрудничеству Михаил Швыдкой заявил, что восстановление сирийской Пальмиры может занять около 5 или 7 лет, добавив, что оценка размера потерь позволит точно определить период, необходимый для восстановления.

Швыдкой также отметил, что в России есть много экспертов, которые специализируются на охране исторического наследия, а именно эксперты Эрмитажа, Пушкинского музея и Музея Востока. Он подчеркнул, что Россия способна помочь Сирии в восстановлении Пальмиры.

Возвращаясь к потенциалу информационных технологий для модернизации сирийского туристского сектора, отметим, что современные технологические инструменты способны значительно смягчить негативные последствия политикоэкономической нестабильности, в состоянии которой сейчас находится Сирия.

Министерство туризма Сирии в настоящее время прорабатывает планы по переходу туризма на рельсы цифровой экономики. В частности, в будущем предполагается особый акцент сделать на реализации 
концепций электронного туризма и электронного маркетинга. Так, например, для продвижения в сети Интернет было предложено использовать новый механизм: Сирия будет присутствовать на странице поисковой системы Google и на спутниковом канале National Geographic, а также в брошюрах, которые продаются в туристских офисах по всему миру. Также планируется привлечение знаменитостей (артистов, политиков и др.) с целью освещения этих визитов в СМИ для формирования позитивного имиджа страны [1].

\section{Заключение}

Исследование принципа комплексного развития туризма в политически нестабильных странах на примере Сирийской Арабской Республики показало, что максимальный положительный эффект на развитие туристского сектора экономики способно оказать использование современных технологий. Информационные технологии и цифровые инструменты в секторе туризма применяются для изуче- ния тенденций и предпочтений туристов, внедрения электронных методов, продвижения туризма и способны в значительной степени повысить эффективность функционирования туристского рынка. Особое значение имеет реализация комплексной стратегии по модернизации сектора туризма со стороны государства, которое обладает наибольшим потенциалом для сохранения и развития туристского рынка в условиях политико-экономической нестабильности.

Индустрия туризма в силу своих объективных особенностей наиболее уязвима в кризисное для того или иного государства время. Тем не менее предложенные рекомендации способны нивелировать негативное влияние кризиса на туристский сектор и направлены на выработку плана антикризисного управления, создание целевой группы по управлению кризисными ситуациями в туризме и установление партнерских отношений с широким кругом национальных и глобальных акторов.

\section{Список литературы}

1. Ассаф Б., Махлюф А. Оценка современного состояния и перспектив восстановления сектора гостиничных услуг в Сирии // Современные инструменты и техники организации личной работы руководителя : материалы Международной научно-практической конференции. - Тамбов : ТГУ им. Г. Р. Державина, 2017. - С. 106-117.

2. Гостиничный сектор: кризис стратегии [Электронный ресурс]. - URL: http:/ / www.arabianindustry.com (дата обращения: 10.03.2019).

3. Карпунина Е. К., Махлюф А. Влияние социальных медиа на развитие туризма и гостиничного бизнеса // РИСК: Ресурсы, Информация, Снабжение, Конкуренция. - 2017. № 2. - С. 166-169.

4. Махлюф А. Особенности функционирования гостиничных предприятий в условиях нестабильности / / Финансовая экономика. - 2018. - № 9. - С. 276-279.

5. Морозов М. А. Новая парадигма развития туризма и индустрии гостеприимства в условиях цифровой экономики // Вестник Российского нового университета. Серия: Человек и общество. - 2018. - № 1. - С. 135-141.

6. Морозов М. А. Инфраструктурное обеспечение предпринимательской деятельности в туризме : монография. - М. : РосНОУ, 2005.

7. Скобкин С. С. Модель управления индустрией гостеприимства // РИСК: Ресурсы, Информация, Снабжение, Конкуренция. - 2012. - № 3. - С. 373-377.

\section{References}

1. Assaf B., Makhlyuf A. Otsenka sovremennogo sostoyaniya i perspektiv vosstanovleniya sektora gostinichnykh uslug $\mathrm{v}$ Sirii [Assessment of the Current State and Prospects for 
Restoring the Hotel Services Sector in Syria]. Sovremennye instrumenty $i$ tekhniki organizatsii lichnoy raboty rukovoditelya, materialy Mezhdunarodnoy nauchno-prakticheskoy konferentsii. [Today's Tools and Methods of Organizing Personal Work of the Executor: materials of the International Conference]. Tambov, TGU named after Derzhavin, 2017, pp. 106-117. (In Russ.).

2. Gostinichnyy sektor: krizis strategii [Hotel Sector: Crisis of Strategy] [E-resource]. (In Russ.). Available at: http:/ / www.arabianindustry.com (accessed 10.03.2019).

3. Karpunina E. K., Makhlyuf A. Vliyanie sotsialnykh media na razvitie turizma i gostinichnogo biznesa [The Impact of Social Media on the Development of Tourism and Hotel Business]. RISK: Resursy, Informatsiya, Snabzhenie, Konkurentsiya [Risk: Resources, Information, Progress, Competition], 2017, No. 2, pp. 166-169. (In Russ.).

4. Makhlyuf A. Osobennosti funktsionirovaniya gostinichnykh predpriyatiy v usloviyakh nestabilnosti [Features of Functioning of Hotel Enterprises in Conditions of Instability]. Finansovaya ekonomika [Financial Economy], 2018, No. 9, pp. 276-279. (In Russ.).

5. Morozov M. A. Novaya paradigma razvitiya turizma i industrii gostepriimstva $v$ usloviyakh tsifrovoy ekonomiki [A New Paradigm for the Development of Tourism and the Hospitality Industry in the Digital Economy]. Vestnik Rossiyskogo novogo universiteta. Seriya: Chelovek $i$ obshchestvo [Bulletin of the Russian New University. Series: Man and Society], 2018, No. 1, pp. 135-141. (In Russ.).

6. Morozov M. A. Infrastrukturnoe obespechenie predprinimatelskoy deyatelnosti v turizme, monografiya [Infrastructure Support for Business Activities in Tourism, monograph]. Moscow, RosNOU, 2005. (In Russ.).

7. Skobkin S. S. Model upravleniya industriey gostepriimstva [The Management Model of the Hospitality Industry]. RISK: Resursy, Informatsiya, Snabzhenie, Konkurentsiya [Risk: Resources, Information, Progress, Competition], 2012, No. 3, pp. 373-377. (In Russ.).

\section{Сведения об авторе}
Агяд Махлюф
аспирант кафедры индустрии гостеприимства, туризма и спорта РЭУ им. Г. В. Плеханова.
Адрес: ФГБОУ ВО «Российский экономический университет имени Г. В. Плеханова», 117997, Москва, Стремянный пер., д. 36.
E-mail: aghiodmak1987@gmail.com

\section{Information about the author}

Aghiad Makhlouf

Post-Graduate Student of the

Academic Department of Hospitality,

Tourism and Sports

of the PRUE.

Address: Plekhanov Russian University

of Economics, 36 Stremyanny Lane,

Moscow, 117997, Russian Federation.

E-mail: aghiodmak1987@gmail.com 